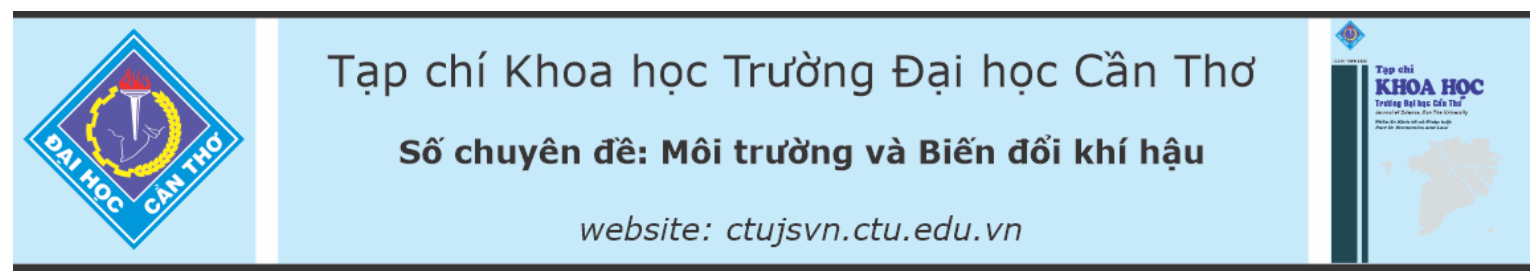

DOI:10.22144/ctu.jsi.2021.039

\title{
LOẠI BỎ CHLORPYRIFOS ETHYL TRONG NƯỚC BĂNG THAN SINH HỌC TRẤU
}

Trần Đức Thạnh, Nguyễn Thị Mỹ Tiên, Nguyễn Hữu Chiếm và Nguyễn Văn Công*

Khoa Môi truờng và Tài nguyên Thiên nhiên, Truờng Đại học Cần Tho

*Người chịu trách nhiệm về bài viết: Nguyễn Văn Công (email: nvcong@ctu.edu.vn)

\section{Thông tin chung:}

Ngày nhận bài: $12 / 04 / 2021$

Ngày nhận bài sủa: 22/10/2021

Ngày duyệt đăng: 15/11/2021

Title:

Removing chlorpyrifos ethyl in water by rice husk biochar

\section{Tù khóa:}

Chlorpyrifos ethyl, hấp phu, than sinh học trấu, thuố bảo vệ thực vật

\section{Keywords:}

Adsorption, chlorpyrifos ethyl, pesticides, rice husk biochar

\begin{abstract}
Rice husk biochar, which was produced at $500^{\circ} \mathrm{C}, 700^{\circ} \mathrm{C}$ and $900^{\circ} \mathrm{C}$ to adsorb chlorpyrifos ethyl (CE) in water, was used in this study. Three treatments of rice husk biochar and control treatment (no biochar) were conducted with three replicates. At each replication, one gram $(1 \mathrm{~g})$ of biochar was added into $200 \mathrm{~mL} C E$ solution and then shook at 125 rounds per minute for 60, 120, 180 and 300 minutes. Afterwards, solutions were filtered through a filter paper. The solution was reserved for analyzing the remaining $C E$ by chromatography. The results showed that rice husk biochar had the ability to adsorb CE quickly during 60 minutes of contact, then adsorption ability was gradually reduced and saturated at 120 minutes in shaking conditions. The average $C E$ adsorption capacity of rice husk biochar was produced at $500^{\circ} \mathrm{C}, 700^{\circ} \mathrm{C}$ and $900^{\circ} \mathrm{C}$ in 300 minutes were $303.40 \pm 24.10 \mu \mathrm{g} / \mathrm{g}, 328.59 \pm 1.47 \mu \mathrm{g} / \mathrm{g}$ and $323.68 \pm 3.82 \mu \mathrm{g} / \mathrm{g}$, respectively. Studying the adsorption capacity of rice husk biochar for some other pesticides was necessary to show the applicability of rice husk biochar in the adsorption of pesticides.
\end{abstract}

\section{TÓM TẮT}

Than sinh học trấu được sản xuất ở $500^{\circ} \mathrm{C}, 700^{\circ} \mathrm{C}$ và $900^{\circ} \mathrm{C}$ đurợc sủ dụng trong nghiên cưu để hấp phu chlorpyrifos ethyl (CE) trong nước. Ba nghiệm thức than và đối chưng (không than) được bố trí với 3 lần lạ̣p lại. Ở mồi lần lạpp lại, $1 \mathrm{~g}$ than được cho vào $200 \mathrm{~mL}$ dung dịch $C E$ và lắc ở tốc độ 125 vòng/phút trong 60, 120, 180 và 300 phút. Sau đó, dung dịch được lọc qua giấy lọc rồi trũ để phân tích CE còn lại trong nước bằng phuoong pháp sắc ký. Kết quả cho thấy than sinh hoc trấu có khả năng hấp phu CE nhanh trong 60 phút đầu, sau đó giảm dần và bão hòa ở 120 phút trong điều kiện lắc. Trung bình khả năng hấp phu CE của than trấu được sản xuất ở $500^{\circ} \mathrm{C}, 700^{\circ} \mathrm{C}$ và $900^{\circ} \mathrm{C}$ trong 300 phút lần luợt là $303,4 \pm 24,10$ $\mu \mathrm{g} / \mathrm{g}, 328,59 \pm 1,47 \mu \mathrm{g} / \mathrm{g}$ và 323,68 $33,82 \mu \mathrm{g} / \mathrm{g}$. Nghiên cứu khả năng hấp phu của than này đối với một số thuốc khác là cần thiết để đưa ra khả năng ưng dụng của than sinh học trấu trong hấp phụ thuốc bảo vệ thực vật.

\section{GIỚI THIÊU}

Đồng bằng sông Cửu Long (ĐBSCL) là vùng canh tác lúa trọng điểm của Việt Nam. Sản lượng lúa ở ĐBSCL luôn chiếm hơn $50 \%$ so với toàn Việt Nam trong khi diện tích chỉ khoảng 12\% diện tích toàn quốc. Nhằm gia tăng năng suất lúa để duy trì sản lượng đạt năng suất cao thì ngoài áp dụng các biện pháp kỹ thuật canh tác tiên tiến, việc sử dụng thuốc bảo vệ thực vật (BVTV) trên đồng ruộng ở ĐBSCL cũng gia tăng. Trong danh mục thuốc BVTV được phép sử dụng ở Việt Nam năm 2017 
(Bộ Nông nghiệp và Phát triển Nông thôn, 2017) có 1.773 hoạt chất với 4.237 sản phẩm thương mại được phép lưu hành, trong đó chlorpyrifos ethyl là hoạt chất thuốc BVTV có trong nhiều tên thương mại và được sử dụng phổ biến trong canh tác nông nghiệp (Nguyễn Văn Toàn và Nguyễn Văn Công, 2017), thuốc chuyên trị các loại sâu đục thân, đục bẹ và cuốn lá và có độc tính cao. Chlorpyrifos ethyl ở nồng độ $27,4 \mathrm{ppb}$ đã làm chết $50 \%$ cá lóc cỡ giống (Nguyễn Anh Tuấn và ctv., 2015). Ngoài ra, khi sử dụng thuốc BVTV chỉ có khoảng 50\% bám trên cây trồng, phần còn lại rơi vào môi trường (Lê Huy Bá và ctv., 2005). Do đó, việc sử dụng thuốc $B V T V$ có nhiều nguy cơ làm nhiễm bẩn môi trường và gây độc cho sinh vật khác.

Than sinh học có nhiều nhóm chức năng như carboxylic, hydroxyl... có khả năng hấp phụ nhiều chất ô nhiễm khác nhau (Ahmad et al., 2014; Xiang et al., 2020). Than sinh học đã được ứng dụng trong tạo các cột lọc của máy lọc nước, trong hệ thống xử lý các khí độc hại, trong mặt nạ hay khẩu trang chống độc... Chen et al. (2008) cho thấy rằng than sinh học có khả năng hấp phụ naphthalene, nitrobenzene và $m$-dinitrobenzene và có thể được sử dụng như một chất hấp phụ để loại bỏ các chất ô nhiễm hữu cơ độc hại như thuốc BVTV trong nước. Ngoài ra, than sinh học có khả năng hấp phụ hiệu quả các độc chất có nguồn gốc từ thuốc $B V T V$ và các độc chất hữu cơ khác trong môi trường đất, nước và trầm tích như hydro carbon thơm (Polycyclic aromatic hydrocarbons - PAHs), thuốc trừ cỏ Atrazine và Simazine (Zheng et al., 2010), Diuron (Yu et al., 2006), Acetochlor (Spokas et al., 2009), terbuthylazine (Wang et al., 2010), thuốc trừ sâu Carbofuran (Yu et al., 2006), Fipronil và thuốc trù̀ bệnh Pyrimethanil (Yu et al., 2010). Do đó, than sinh học là vật liệu có tiềm năng sử dụng để hấp phụ thuốc BVTV.

Trấu là loại phụ phẩm trong canh tác lúa và có lượng rất lớn ở ĐBSCL. Hiện nay, trấu được sử dụng làm chất đốt trực tiếp cho các lò hơi, hoặc được ép thành củi trấu để giảm thể tích. Vỏ trấu có tính đồng nhất cao nên khi tạo than sinh học sẽ có tính đồng nhất cao. Nghiên cứu của Phuong et al. (2016) cho thấy than sinh học trấu có khả năng hấp phụ iodine. Tuy nhiên, khả năng hấp phụ các chất ô nhiễm trong môi trường như hoạt chất thuốc trừ sâu như chlorpyrifos ethyl của than sinh học trấu chưa được nghiên cứu. Do đó, nghiên cứu này được thực hiện nhằm đánh giá khả năng hấp phụ chlorpyrifos ethyl của than sinh học trấu, góp phần làm cơ sở cho các nghiên cứu tiếp theo về ứng dụng than sinh học trấu trong hấp phụ nước ô nhiễm các hoạt chất thuốc BVTV.

\section{VÂT LIÊU VÀ PHƯƠNG PHÁP NGHIẾN CÚU}

\subsection{Vật liệu nghiên cứu}

Thuốc BVTV hoạt chất chlorpyrifos ethyl có tên thương mại Vitashield 40EC, chứa $40 \%$ hoạt chất chlorpyrifos ethyl (400 g/L).

Than sinh học sản xuất từ trấu $(O$. sativa $L$., $\mathrm{OM} 5451)$ ở $500^{\circ} \mathrm{C}, 700^{\circ} \mathrm{C}$ và $900^{\circ} \mathrm{C}$ bằng lò nung (VMF-165, Nhật Bản).

Phương pháp sản xuất than sinh học: Trấu được xay thành hạt kích thước $1 \mathrm{~mm}$, nhiệt phân ở 3 mức nhiệt độ $500^{\circ} \mathrm{C}, 700^{\circ} \mathrm{C}$ và $900^{\circ} \mathrm{C}$ trong lò nung và sản phẩm được sấy khô ở $105^{\circ} \mathrm{C}$. Khí nitơ được bơm vào lò với lưu lượng $3 \mathrm{~L} /$ phút để loại bỏ không khí bên trong lò. Sau đó, nhiệt độ lò được nâng từ nhiệt độ phòng lên $500^{\circ} \mathrm{C}, 700^{\circ} \mathrm{C}$ và $900^{\circ} \mathrm{C}$ với tốc độ gia nhiệt $10^{\circ} \mathrm{C} /$ phút (Loc et al., 2018). Nhiệt độ này được ổn định trong 2 giờ và sau đó sản phẩm được để nguội đến nhiệt độ phòng.

Than sinh học trấu được sấy ở $105^{\circ} \mathrm{C}$ trong 24 giờ để đồng nhất độ ẩm trước khi cân để bố trí thí nghiệm.

\subsection{Bố trí thí nghiệm}

Thí nghiệm được bố trí với 3 lần lặp lại cho các nghiệm thức sau:

- Nghiệm thức đối chứng (không than) và có thuốc BVTV để theo dõi diễn biến nồng độ thuốc dưới tác động của các yếu tố môi trường (như ánh sáng, nhiệt độ).

- Nghiệm thức than sinh học trấu được sản xuất ở $500^{\circ} \mathrm{C}, 700^{\circ} \mathrm{C}, 900^{\circ} \mathrm{C}$ và có thuốc $\mathrm{BVTV}$ để theo dõi diễn biến nồng độ thuốc dưới tác động của các yếu tố môi trường (như ánh sáng, nhiệt độ) và sự hấp phụ của than sinh học.

\section{Bảng 1. Thông tin các nghiệm thức thí nghiệm}

\begin{tabular}{lcc}
\hline Nghiệm thức & Khối lượng than $(\mathbf{g})$ & Thời gian tiếp xúc với than (phút) \\
\hline ĐC_Không than & 0 & $60 ; 120 ; 180 ; 300$ \\
NT1_Than trấu $500^{\circ} \mathrm{C}$ & 1 & $60 ; 120 ; 180 ; 300$ \\
NT2_Than trấu $700^{\circ} \mathrm{C}$ & 1 & $60 ; 120 ; 180 ; 300$ \\
NT3_Than trấu $900^{\circ} \mathrm{C}$ & 1 & $60 ; 120 ; 180 ; 300$ \\
\hline
\end{tabular}


Dung dịch chlorpyrifos ethyl $2000 \mu \mathrm{g} / \mathrm{L}$ được chuẩn bị bằng cách lấy $1 \mathrm{~mL}$ Vitashield $40 \mathrm{EC}$ pha thành $100 \mathrm{~mL}$, sau đó lấy $0,5 \mathrm{~mL}$ dung dịch vừa pha hoà tan với nước cất thành dung dịch $1000 \mathrm{~mL}$.

Để đảm bảo thấy được khả năng bão hoà hấp phụ của than, kết quả các thí nghiệm thăm dò cho thấy rằng sử dụng $1 \mathrm{~g}$ than là tối ưu nhất. Trong thí nghiệm này, cho $1 \mathrm{~g}$ than vào bình tam giác thủy tinh $250 \mathrm{~mL}$ và cho $200 \mathrm{~mL}$ dung dịch thí nghiệm chlorpyrifos ethyl $2000 \mu \mathrm{g} / \mathrm{L}$ vào, sau đó dùng giấy wrap đậy lại đưa vào máy lắc và lắc ở tốc độ 125 vòng/phút.

Mẫu được thu trước khi cho than vào (sau khi pha), sau $60,120,180$ và 300 phút để phân tích dư lượng thuốc còn lại trong nước. Sau khi thu, mẫu được lọc qua giấy lọc (Whatman) để loại bỏ than. Giấy lọc có kích thước $11 \mu \mathrm{m}$. Mẫu đối chứng (không than) cũng được lọc. Sau khi lọc xong mẫu được đo $\mathrm{pH}$. Mẫu được gửi đến phòng thí nghiệm của Trung tâm Dịch vụ phân tích thí nghiệm Thành phố Hồ Chí Minh - Chi nhánh Cần Thơ (CASE Cần Thơ) để phân tích dư lượng thuốc còn lại. Chlorpyrifos ethyl đã được phân tích bằng GC-MS.

\subsection{Tính toán kết quả}

Hiệu suất làm giảm nồng độ

$$
\mathrm{H}(\%)=100-\frac{\mathrm{C}_{t}}{\mathrm{C}_{0}} * 100
$$

Trong đó:

H: là hiệu suất làm giảm nồng độ so với nồng độ ban đầu $(\%)$

$\mathrm{C}_{\mathrm{t}}$ : Nồng độ còn lại sau $\mathrm{t}$ giờ tiếp xúc $(\mu \mathrm{g} / \mathrm{L})$

$\mathrm{C}_{0}$ : Nồng độ thuốc ban đầu (trước khi cho than vào) $(\mu \mathrm{g} / \mathrm{L})$

Khả năng hấp phụ thuốc của than:

$$
K(\mu g / g)=\frac{\left[\left(C_{o}-C_{t t h a n}\right)-\left(C_{o}-C_{t \mathrm{dc}}\right)\right] * \mathrm{~V}}{\mathrm{~W}}
$$

Trong đó:
$\mathrm{K}$ : là lượng thuốc được than hấp phụ $(\mu \mathrm{g} / \mathrm{g})$

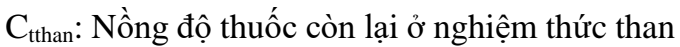
sau $\mathrm{t}$ giờ tiếp xúc $(\mu \mathrm{g} / \mathrm{L})$

$\mathrm{C}_{\mathrm{tdc}}$ : Nồng độ thuốc còn lại ở nghiệm thức đối chứng sau $\mathrm{t}$ giờ tiếp xúc $(\mu \mathrm{g} / \mathrm{L})$

W: là lượng than cho vào dung dịch thuốc $(1 \mathrm{~g})$

V: là thể tích dung dịch thuốc $(0,2 \mathrm{~L})$

\subsection{Phương pháp phân tích và xử lý số liệu}

Phần mềm Microsoft Excel được sử dụng để tổng hợp số liệu và vẽ đồ thị. Phần mềm IBM SPSS Statistics 20.0 được sử dụng để phân tích ANOVA, so sánh sự khác biệt giữa các nghiệm thức qua phép kiểm định Duncan 5\%.

\section{KẾT QUẢ VÀ THẢO LUẬN}

\section{1. Ảnh hưởng của than sinh học trấu đến pH của dung dịch}

Kết quả nghiên cứu ở Hình 1 cho thấy các nghiệm thức có sự khác biệt có ý nghĩa $(p<0,05)$. Giá trị pH trung bình của nghiệm thức không có than (ĐC) là $7,59 \pm 0,05$. Khi đưa than vào $\mathrm{pH}$ trung bình tăng lên, ở nghiệm thức than $700^{\circ} \mathrm{C}(\mathrm{NT} 2)$ và $900^{\circ} \mathrm{C}$ (NT3) không có khác biệt ý nghĩa thống kê $(\mathrm{p}>0,05)$. Theo Loc et al. (2018) cũng cho thây $\mathrm{pH}$ của than sinh học trấu này tăng khi nhiệt độ tạo than tăng. Shi et al. (2017) cũng cho thấy sự tăng pH đất khi có bổ sung than sinh học và giải thích cơ chế do tính kiềm của than. Trong nghiên cứu này, để giải thích rõ cơ chế tại sao $\mathrm{pH}$ tăng khi cho than vào thì cần phải có những nghiên cứu tìm hiểu về tính kiềm của than. Về mặt lý thuyết, sự gia tăng nhiệt độ nhiệt phân có thể loại bỏ các nhóm chức có tính axit (như các nhóm quinon, chromene và diketone); do đó, biochars có xu hướng kiềm hơn (Mukherjee et al., 2011; Tsai, 2017). pH của than sinh học được sản xuất từ cây thân gỗ (tràm, tre) và lục bình có xu hướng tăng khi nhiệt độ tăng từ $500^{\circ} \mathrm{C}$ đến $900^{\circ} \mathrm{C}$ (Conz et al., 2017; Loc et al., 2018; Sun et al., 2017). 


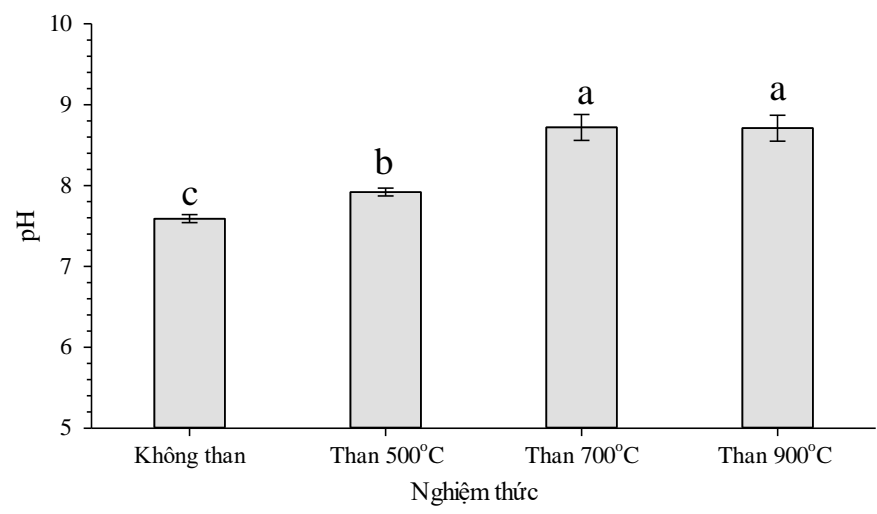

Hình 1. pH của các nghiệm thức khi cho than vào

\subsection{Sự thay đổi nồng độ theo thời gian}

Kết quả nghiên cứu cho thấy nồng độ chlorpyrifos ethyl ở các nghiệm thức ĐC, NT1, NT2 và NT3 giảm theo thời gian và có khác biệt ý nghĩa thống kê $(\mathrm{p}<0,05)$ (Bảng 2).

Bảng 2. Nồng độ thuốc theo thời gian ở các nghiệm thức

\begin{tabular}{|c|c|c|c|c|c|}
\hline \multirow{2}{*}{ Nghiệm thức } & \multicolumn{5}{|c|}{ Thời gian (Phút) } \\
\hline & $\mathbf{0}$ & 60 & 120 & 180 & 300 \\
\hline & $92^{\mathrm{Aa}}$ & 1400 & $4,18^{\mathrm{Ca}}$ & $1122,67 \exists$ & $3,91^{\mathrm{Ca}}$ \\
\hline & $2,92^{\text {Aa }}$ & $209,57 \pm 89,04^{\mathrm{Bb}}$ & $6,26^{\mathrm{Cb}}$ & $164,47 \pm 83,71^{\mathrm{Cb}}$ & $3,72^{\mathrm{Cb}}$ \\
\hline $\mathrm{NT}$ & 1705,5 & $68,07 \pm 2,80^{\mathrm{Bc}}$ & $53,30 \pm 13,43^{\mathrm{Cc}}$ & $53,07 \pm 17,06^{\mathrm{Cc}}$ & $43,93 \pm 15,23^{\mathrm{Cc}}$ \\
\hline NT3_900 $90^{\circ} \mathrm{C}$ & $1705,57 \pm 222,92^{\mathrm{Aa}}$ & $56,57 \pm 4,55^{\mathrm{Bc}}$ & $44,37 \pm 2,44^{\mathrm{Cc}}$ & $47,27 \pm 13,03^{\mathrm{Cc}}$ & $44,77 \pm 17,18^{\mathrm{Cc}}$ \\
\hline
\end{tabular}

Ghi chú: Số liệu được trình bày dạng Trung bình \pm Độ lệch chuẩn, $n=3$

Các giá trị trong cùng một hàng có cùng kí tư $(A, B, C)$ và các giá trị trong cùng một cột có cùng kí tư $(a, b, c)$ khác biệt không có ýn nghĩa thống kê 5\% qua phép thử Duncan.

Ở nghiệm thức đối chứng (không có than), nồng độ ban đầu là $1705,57 \pm 222,92 \mu \mathrm{g} / \mathrm{L}$ sau thời gian 60 phút, 120 phút, 180 phút và 300 phút đã giảm xuống với nồng độ còn lại lần lượt là $1400,53 \pm 58,50 \mu \mathrm{g} / \mathrm{L}$, $1201,20 \pm 344,18 \mu \mathrm{g} / \mathrm{L}, \quad 1122,67 \pm 162,11 \mu \mathrm{g} / \mathrm{L}$ và $1016,13 \pm 8,91 \mu \mathrm{g} / \mathrm{L}$ (Bảng 2). Mặc dù nồng độ chlorpyrifos ethyl có xu hướng giảm theo thời gian nhưng khác biệt không có ý nghĩa thống kê ( $p>0,05)$. Sự giảm này có thể do sự bay hơi của thuốc, phân hủy dưới ánh sáng và khả năng hấp phụ vào giấy lọc sau khi mẫu được lọc qua. Chlorpyrifos có áp suất bốc hơi ở $25^{\circ} \mathrm{C}$ là $1,87 \times 10^{-5} \mathrm{mmHg}$ và có thể gây độc qua đường hô hấp (Tomlin, 2006). Thời gian bán hủy trong nước do bốc hơi khoảng 3,5-15 ngày, do ánh sáng khoảng 7 ngày (Kamrin, 1997).

Kết quả nghiên cứu cho thấy nồng độ chlorpyrifos ethyl ở NT1, NT2 và NT3 giảm theo thời gian và trong 60 phút đầu nồng độ chlorpyrifos ethyl giảm lần lượt còn $209,57 \pm 89,04 \mu \mathrm{g} / \mathrm{L}$, $68,07 \pm 2,80 \mu \mathrm{g} / \mathrm{L}$ và $56,57 \pm 4,55 \mu \mathrm{g} / \mathrm{L}$ (Bảng 2 ), nồng độ chlorpyrifos ethyl của 3 nghiệm thức có than sinh học trấu giảm dần theo thời trong khoảng
120 - 300 phút nhưng khác biệt không có ý nghĩa thống kê $(\mathrm{p}>0,05)$, có thể thấy rằng than không còn hấp phụ hoặc đã bão hòa hấp phụ. Việc lắc dung dịch cũng có vai trò quan trọng trong làm tăng khả năng tiếp xúc của dung dịch chlorpyrifos ethyl với bề mặt của than, nhờ vậy mà thời gian bão hòa hấp phụ nhanh. Sự giảm nồng độ của 3 nghiệm thức này do sự bay hơi của thuốc, phân hủy dưới ánh sáng và khả năng hấp phụ vào giấy lọc sau khi mẫu được lọc qua và phần lớn là do hấp phụ của than sinh học trấu được tạo ra ở $500^{\circ} \mathrm{C}, 700^{\circ} \mathrm{C}$ và $900^{\circ} \mathrm{C}$, vì than sinh học có nhiều nhóm chức năng như carboxylic, hydroxyl nên chlorpyrifos ethyl chỉ thủy phân mạnh khi môi trường có tính kiềm (Tomlin, 1994). Theo kết quả nghiên cứu của Lê Trường và ctv. (2005) cho thấy độ thủy phân của chlorpyrifos ethyl tăng khi độ $\mathrm{pH}$ tăng. So với NT2 và NT3 thì NT1 có nồng độ chlorpyrifos ethyl còn lại qua các khoảng thời gian 60 - 300 phút cao hơn (khoảng 3 lần) và khác biệt có ý nghĩa thống kê $(p<0,05)$. Giữa NT2 và NT3 thì nồng độ chlorpyrifos ethyl còn lại khác biệt không có ý nghĩa thống kê (p>0,05) ở 60 phút, 120 phút, 180 phút và 300 phút. 


\subsection{Hiệu suất giảm nồng độ thuốc giữa các nghiệm thức}

Kết quả cho thấy ở nghiệm thức đối chứng hiệu suất làm giảm nồng độ thuốc chlorpyrifos ethyl từ
$17,88 \pm 9,87 \%$ đến $40,42 \pm 1,50 \%$ so với nồng độ ban đầu và khác biệt có ý nghĩa thống kê $(\mathrm{p}<0,05)$ (Bảng 3).

Bảng 3. Hiệu suất làm giảm chlorpyrifos ethyl của các nghiệm thức so với đầu vào

\begin{tabular}{lrrrr}
\hline \multirow{2}{*}{ Nghiệm thức } & $\mathbf{6 0}$ & \multicolumn{4}{c}{ Thời gian (phút) } \\
\cline { 2 - 5 } & $17,88 \pm 9,87^{\mathrm{Cc}}$ & $\mathbf{1 2 0}$ & $\mathbf{1 8 0}$ & $\mathbf{3 0 0}$ \\
\hline Đối chứng & $29,57 \pm 10,77^{\mathrm{Bc}}$ & $34,18 \pm 13,51^{\mathrm{Ac}}$ & $40,42 \pm 1,50^{\mathrm{Ac}}$ \\
NT1_500 & $87,71 \pm 6,01^{\mathrm{Bb}}$ & $90,74 \pm 3,97^{\mathrm{Ab}}$ & $90,36 \pm 5,51^{\mathrm{Ab}}$ & $91,96 \pm 7,30^{\mathrm{Ab}}$ \\
NT2_700 & $96,01 \pm 0,64^{\mathrm{Ba}}$ & $96,87 \pm 1,08^{\mathrm{Aa}}$ & $96,89 \pm 1,11^{\mathrm{Aa}}$ & $97,42 \pm 0,92^{\mathrm{Aa}}$ \\
NT3_900 & $96,68 \pm 0,66^{\mathrm{Ba}}$ & $97,40 \pm 0,19^{\mathrm{Aa}}$ & $97,23 \pm 1,07^{\mathrm{Aa}}$ & $97,38 \pm 1,29^{\mathrm{Aa}}$ \\
\hline
\end{tabular}

Ghi chú: Số liệu được trình bày dạng Trung bình \pm Độ lệch chuẩn, $n=3$

Các giá trị trong cùng một hàng có cùng ki tục $(A, B, C)$ và các giá trị trong cùng một cột có cùng kí tư $(a, b, c)$ khác biệt không có ý nghĩa thống kê $5 \%$ qua phép thử Duncan

Nghiệm thức NT1 khác biệt có ý nghĩa thống kê $(\mathrm{p}<0,05)$ so với NT2, NT3 về hiệu suất giảm chlorpyrifos ethyl. Ở các thời gian 60 - 300 phút, hiệu suất hấp phụ của NT1 thấp hơn 2 nghiệm thức còn lại, dao động từ $87,71 \pm 6,01-91,96 \pm 7,30 \%$ so với NT2, NT3 lần lượt là từ $96,01 \pm 0,64$ $97,42 \pm 0,92 \% ; 96,68 \pm 0,66-97,40 \pm 0,19 \%$. Điều đó cho thấy hiệu suất hấp phụ tăng khi nhiệt độ tạo than cao hơn. Theo nghiên cứu của Phuong et al. (2016) cho thấy rằng diện tích bề mặt của than trấu Việt Nam tạo ra ở $700^{\circ} \mathrm{C}$ và $800^{\circ} \mathrm{C}$ cao hơn ở $500^{\circ} \mathrm{C}$ và khả năng hấp phụ iodine của than được tạo ra ở $700^{\circ} \mathrm{C}$ cũng cao hơn của than được tạo ra ở $500^{\circ} \mathrm{C}$. Có nghĩa là than được sản xuất ở $700^{\circ} \mathrm{C}$ là có khả năng hấp phụ tốt nhất nhờ diện tích bề mặt cao hơn than được tạo ra ở $500^{\circ} \mathrm{C}$. Có thể đây cũng là lý do hiệu suất làm giảm chlorpyrifos ethyl của than được tạo ra ở nhiệt độ $700^{\circ} \mathrm{C}$ và $900^{\circ} \mathrm{C}$ cao hơn ở $500^{\circ} \mathrm{C}$. Hiệu suất làm giảm nồng độ chlorpyrifos ethyl không thay đổi lớn từ 120 phút trở về sau có thể do than đã bão hòa hấp phụ thuốc. Kết quả phân tích thống kê cho thấy nồng độ chlorpyrifos ethyl còn lại khác biệt không có ý nghĩa $(\mathrm{p}>0,05)$ kể từ 120 phút trở về sau cho tất cả các nghiệm thức có than sinh học trấu.
Ngoài ra, $\mathrm{pH}$ sau khi cho than sinh học trấu vào tăng cao ở nghiệm thức than $700^{\circ} \mathrm{C}(\mathrm{NT} 2)$ và $900^{\circ} \mathrm{C}$ (NT3) hơn ở $500^{\circ} \mathrm{C}$. Theo Xi et al. (2014) nếu pH tăng thì sẽ làm giảm khả năng hấp phụ. Trong thí nghiệm này, $\mathrm{pH}$ không được điều chỉnh ở cùng mức nên có cả yếu tố $\mathrm{pH}$ và diện tích bề mặt ảnh hưởng làm khác nhau về hiệu suất hấp phụ chlorpyrifos ethyl của than sinh học trấu được tạo ra ở các nhiệt độ $500^{\circ} \mathrm{C}, 700^{\circ} \mathrm{C}$ và $900^{\circ} \mathrm{C}$. Do đó, nếu điều chỉnh pH về cùng mức sẽ có so sánh cho thấy vai trò của than sinh học trấu rõ hơn trong hấp phụ chlorpyrifos ethyl.

\subsection{Khả năng hấp phụ chlorpyrifos ethyl của than trấu được tạo ra ở các nhiệt độ khác nhau}

Trong nghiên cứu này, lượng than sử dụng là 1 $\mathrm{g}$ cho $200 \mathrm{~mL}$ dung dịch. Lượng thuốc ở đối chứng không có than vẫn giảm và như đã thảo luận là do bay hơi, ánh sáng, bị hấp phụ vào giấy lọc... Chính vì vậy, thuốc được than hấp phụ sẽ được tính toán dựa vào kết quả lượng chlorpyrifos ethyl giảm ở từng nghiệm thức than trừ đi sự giảm ở nghiệm thức đối chứng là lượng thuốc chlorpyrifos ethyl được 1 $\mathrm{g}$ than hấp phụ.

Bảng 4. Khả năng hấp phụ chlorpyrifos ethyl của các nghiệm thức than sinh học trấu

\begin{tabular}{|c|c|c|c|c|}
\hline \multirow{2}{*}{ Nghiệm thức } & \multicolumn{4}{|c|}{ Thò̀i gian (phút) } \\
\hline & 60 & 120 & 180 & 300 \\
\hline$\overline{\mathrm{NT} 1 \_500^{\circ} \mathrm{C}}$ & $238,19 \pm 17,81^{\mathrm{Bb}}$ & $289,35 \pm 11,25^{\mathrm{Ab}}$ & $284,90 \pm 16,74^{\mathrm{Ab}}$ & $303,40 \pm 25,10^{\mathrm{Ab}}$ \\
\hline $\mathrm{NT} 2 \_700^{\circ} \mathrm{C}$ & $266,49 \pm 0,56^{\mathrm{Ba}}$ & $310,28 \pm 2,69^{\mathrm{Aa}}$ & $307,18 \pm 3,41^{\mathrm{Aa}}$ & $328,59 \pm 1,47^{\mathrm{Aa}}$ \\
\hline NT3_900 ${ }^{\circ} \mathrm{C}$ & $268,79 \pm 0,91^{\mathrm{Ba}}$ & $312,07 \pm 0,49^{\mathrm{Aa}}$ & $312,36 \pm 1,61^{\mathrm{Aa}}$ & $323,68 \pm 3,82^{\mathrm{Aa}}$ \\
\hline
\end{tabular}

Ghi chú: Số liệu được trình bày dạng Trung bình \pm Độ lệch chuẩn, $n=3$

Các giá trị trong cùng một hàng có cùng ki tụ $(A, B, C)$ và các giá trị trong cùng một cột có cùng kí tụ (a, b, c) khác biệt không có ý nghĩa thống kê 5\% qua phép thử Duncan 
Kết quả cho thấy khả năng hấp phụ chlorpyrifos ethyl không khác biệt có ý nghĩa thống kê $(\mathrm{p}>0,05)$ của NT2 và NT3 ở các thời điểm từ 120 phút trở về sau. Khả năng hấp phụ chlorpyrifos ethyl của than trấu được tạo ra ở $500^{\circ} \mathrm{C}(\mathrm{NT} 1)$ thấp hơn ở hai nghiệm thức còn lại (NT2, NT3), khác biệt có ý nghĩa thống kê $(\mathrm{p}<0,05)$ ở tất cả thời điểm (Bảng 4$)$, có thể là do bề mặt than và độ rỗng của than tạo ra ở $700^{\circ} \mathrm{C}$ và $900^{\circ} \mathrm{C}$ nhiều hơn nên nó có khả năng hấp thụ cao hơn. Theo nghiên cứu của Xi et al. (2014), khi than sinh học được sản xuất ở các nhiệt độ khác nhau thì diện tích bề mặt than có sự khác biệt với nhau. Phuong et al. (2018) cũng cho thấy diện tích bề mặt than sinh học trấu tăng khi được sản xuất ở nhiệt độ cao hơn. Than sinh học trấu được ra ở $500^{\circ} \mathrm{C}, 700^{\circ} \mathrm{C}$ và $900^{\circ} \mathrm{C}$ có khả năng hấp phụ chlorpyrifos ethyl có giá trị lần lượt là $238,19 \pm 17,81$ $-303,40 \pm 25,10 \mu \mathrm{g} / \mathrm{g} ; 266,49 \pm 0,56-328,59 \pm 1,47$ $\mu \mathrm{g} / \mathrm{g}$ và $268,79 \pm 0,91-323,68 \pm 3,82 \mu \mathrm{g} / \mathrm{g}$.

Khả năng hấp phụ có biến động theo thời gian nhưng không nhiều và hấp phụ nhanh nhất trong giai đoạn 60 phút đầu. Xi et al. (2014) cũng cho thấy than được tạo ra ở nhiệt độ $300,400,500,600,700^{\circ} \mathrm{C}$ đều tăng khả năng hấp phụ thuốc BVTV pymetrozine theo thời gian và tốc độ hấp phụ ở thời gian đầu là cao (hấp phụ 70 - 80\% trong 1 giờ đầu tiên) và sau đó chậm dần cho đến cân bằng.

Trong nghiên cứu này, $\mathrm{pH}$ dung dịch khá cao $(>7,5)$ nên khả năng hấp phụ có thể bị giảm (Xi et al., 2014). Nếu pH được điều chỉnh ở mức acid thì có thể tăng khả năng hấp phụ của than. Ngoài ra, trong nghiên cứu này dung dịch được lắc trong thời gian lưu nên khả năng tiếp xúc tăng, làm nhanh bão hòa. Trong thực tế áp dụng, nếu không lắc dung dịch thì sự hấp thụ có thể diền ra chậm hơn và lượng được hấp phụ cũng ít hơn nhưng thời gian bão hòa có thể sẽ kéo dài hơn.

Từ kết quả bước đầu phát hiện này, khả năng hấp phụ tối ưu cho $01 \mathrm{~kg}$ than được tạo ra ở nhiệt độ $500^{\circ} \mathrm{C}, 700^{\circ} \mathrm{C}$ và $900^{\circ} \mathrm{C}$ có khả năng hấp phụ 289,35 $\mathrm{g}$ chlorpyrifos ethyl $(=289,35 \mu \mathrm{g} / \mathrm{g} \times 1000 \mathrm{~g})$, $310,28 \mathrm{~g}$ chlorpyrifos ethyl $(=310,28 \mu \mathrm{g} / \mathrm{g}$ x $1000 \mathrm{~g})$ và $312,07 \mathrm{~g}$ chlorpyrifos ethyl $(=312,07 \mu \mathrm{g} / \mathrm{g}$ x 1000 $\mathrm{g})$ được ước tính. Tuy nhiên, số liệu này ước tính cho điều kiện có lắc. Nếu không lắc thì tốc độ hấp phụ có thể chậm hơn. Đây là thông tin quan trọng làm cơ sở ước tính lượng than cần thiết chuẩn bị để quản lý lượng thuốc phát sinh cần xử lý tại các co sở kinh doanh thuốc BVTV. Ngoài ra, trong các hoạt động rửa bình phun hay rửa chai nhiễm thuốc cũng làm phát sinh ô nhiễm và có thể sử dụng than để hấp phụ. Ở những nơi không có nước máy mà phải sử dụng nguồn nước mặt cho sinh hoạt cũng có thể áp dụng lọc qua than để hạn chế rủi ro của các chất ô nhiễm như thuốc BVTV cho sức khỏe.

\section{KẾT LUẬN}

Than sinh học trấu được sản xuất ở ba mức nhiệt độ $500^{\circ} \mathrm{C}, 700^{\circ} \mathrm{C}$ và $900^{\circ} \mathrm{C}$ đều có khả năng hấp phụ thuốc BVTV hoạt chất chlorpyrifos ethyl; khả năng hấp phụ tối ưu khoảng $289,35 \pm 11,25 \mu \mathrm{g} / \mathrm{g}$ đối với than sinh học trấu ở $500^{\circ} \mathrm{C}(\mathrm{NT} 1), 310,28 \pm 2,69 \mu \mathrm{g} / \mathrm{g}$ đối với $700^{\circ} \mathrm{C}(\mathrm{NT} 2)$ và $312,07 \pm 0,49 \mu \mathrm{g} / \mathrm{g}$ đối với $900^{\circ} \mathrm{C}(\mathrm{NT} 3)$. Khả năng hấp phụ nhanh trong thời gian 60 phút tiếp xúc đầu tiên, sau đó giảm dần và đã bão hòa ở 120 phút tiếp xúc trong điều kiện có lắc. Khả năng hấp phụ chlorpyrifos ethyl của than được tạo ra ở $500^{\circ} \mathrm{C}$ thấp hơn ở $700^{\circ} \mathrm{C}$ và $900^{\circ} \mathrm{C}$.

Cần nghiên cứu khả năng hấp phụ một số thuốc BVTV khác của than trấu sản xuất ở các nhiệt độ khác nhau và ảnh hưởng của $\mathrm{pH}$ đến khả năng hấp phụ của than.

\section{LỜI CẢM ƠN}

Nghiên cứu này được tài trợ bở Dự án Nâng cấp Trường Đại học Cần Thơ VN14-P6 bằng nguồn vốn vay ODA từ chính phủ Nhật Bản.

\section{TÀI LIỆU THAM KHẢO}

Ahmad, M., Rajapaksha, A. U., Lim J. E., Zhang M., Bolan N., Mohan D., Vithanage M., Lee S. S., \& Ok Y. S. (2014). Biochar as a sorbent for contaminant management in soil and water: A review. Chemosphere, (99), 19-33.

Bộ Nông nghiệp và Phát triển Nông thôn. (2017). Danh muc thuốc BVTV được phép sủ dụng, hạn chế sử dụng, cấm sử dụng ở Việt Nam. Thông tư số 15/2017/TT-BNNPTNT ngày 14/8/2017.

Conz, R. F., Abbruzzini, T. F., de Andrade, C. A., Milori, D. M., \& Cerri, C. E. (2017). Effect of pyrolysis temperature and feedstock type on agricultural properties and stability of biochars,". Agric Sci., 8(9), 914.

Chen, B., Zhou, D. \& Zhu L. (2008). Transitional adsorption and partition of nonpolar and polar aromatic contaminants by biochars of pine needles with different pyrolytic temperatures. Environmental Science \& Technology. (14), 5137-43.

http://pubs.acs.org/doi/pdf/10.1021/es8002684.

Kamrin, M.A. (1997). Pesticides Profiles Toxicity, Environmental Impact and Fate. Lewis Publisher, Boca Raton, New York.

Lê Huy Bá \& Lâm Minh Triết. (2005). Sinh thái môi truờng úng dụng. Nhà Xuất Bản Khoa Học và Kỹ Thuật. 
Lê Trường, Nguyễn Trần Oánh \& Đào Trọng Ánh. (2005). Tù điển sủ dụng thuốc bảo vệ thưc vật ở Việt Nam. Nhà xuất bản Nông Nghiệp. Hà Nội.

Loc, X., Nguyen, Phuong T. M. Do, Chiem H. Nguyen, Ryota Kose, Takayuki Okayama, Thoa N. Pham, Phuong D. Nguyen \& Takayuki Miyanishi. (2018). Properties of biochars prepared from local biomass in the Mekong delta, Vietnam, BioResources, 13(4), 7325-7344.

Mukherjee, A., Zimmerman, A. R., \& Harris, W. (2011). Surface chemistry variations among a series of laboratory-produced biochars, Geoderma 163(3-4), 247-255. Doi: 10.1016/j.geoderma.2011.04.021

Nguyễn Anh Tuấn, Nguyễn Văn Công \& Châu Thành Tươi. (2015). Ảnh hưởng của thuốc bảo vệ thực vật chứa hoạt chất chlorpyrifos ethyl lên chilinesterase ở cá lóc giai đoạn giống. Tạp chí khoa học và công nghệ Việt Nam, 2(9), 33-37.

Nguyễn Văn Toàn \& Nguyễn Văn Công (2018). Hiện trạng sử dụng thuốc bảo vệ thực vật ở một số vùng canh tác lúa đồng bằng sông Cửu Long. Tạp chi Tài nguyên và Môi trương, 5(283), 26-30.

Phuong, D. T. M, Loc, X. Nguyen, Taro Ueda, Takayuki Miyanishi, Takayuki Okayama \& Ryota Kose. (2018). Properties and potential use of biochars from residues of two rice varieties, Japanese Koshihikari and Vietnamese IR50404. Journal of Material Cycles and Waste Management., (21), 98-106.

Phuong, D. T. M., Miyanishi, T., Okayama, T., \& Kose R. (2016). Pore characteristics and adsorption capacities of biochars derived from rice residues as affected by variety and pyrolysis temperture. American Journal of Innovative Research and Applied Sciences, 2(5), 179-189.

Shi R., Hong Z., Li J., Jiang J., Baquy M. A., Xu R. \& Qian W. (2017). Mechanisms for increasing the $\mathrm{pH}$ euffering capacity of an acidic ultisol by crop residue-derived biochars. Journal of Agricultural and Food Chemistry, 65(37), 8111-8119.

Spokas, K., Koskinen, W. C., Baker, J. M. \& Reicosky, D. C. (2009). Impacts of woodchip biochar additions on greenhouse gas production and sorption/degradation of two herbicides in a Minnesota soil. Chemosphere, 77(4), 574-581.
Sun, X., Shan, R., Li, X., Pan, J., Liu, X., Deng, R., \& Song, J. (2017). Characterization of 60 types of Chinese biomass waste and resultant biochars in terms of their candidacy for soil application, Gcb Bioenergy., 9(9), 1423-1435.

Tomlin, C.D.S (1994). The pesticide mamual: Incorporating the Agrochemicals Handbook, $10^{\text {th }}$, British Crop Protection Publication, (pp. $200-437)$.

Tomlin, C.D.S. (2006). The Pesticide Manual, A World Compendium, $14^{\text {th }}$ Edition British Crop Protection Council. Alton, Hampshire, 186-187.

Tsai, W. T. (2017). The potential of pyrolysing exhausted coffee residue for the production of biochar, in: Handbook of Coffee Processing ByProducts: Sustainable Application, C. M. Galanakis (ed.), Academic Press, Cambridge, MA, (pp. 299-322).

Wang, H., Lin, K., Hou, Z., Richardson, B., and Gan, J. (2010). Sorption of the herbicide terbuthylazine in two New Zealand forest soils amended with biosolids and biochars. Journal of Soils and Sediments, 10(2), 283-289. doi:10.1007/s11368-009-0111-z.

Xi, X., J. Yan, G. Quan and \& L. Cui. (2014). Removal of the Pesticide Pymetrozine from Aqueous Solution by Biochar Produced from Brewer's Spent Grain at Different Pyrolytic Temperatures. BioResources, 9(4), 7696-7709.

Xiang W., Zhang X., Chen J., Zou W., He F., Hu X., Tsang D. C.W., Ok Y. S., \& Gao B. (2020). Biochar technology in wastewater treatment: A critical review. Chemosphere, 252. https://doi.org/10.1016/j.chemosphere.2020.126539

Yu, XY. Pan, LG. Ying, GG. \& Kookana, R. S. (2010). Enhanced and irreversible sorption of pesticide pyrimethanil by soil amended with biochars. Journal of Environmental Sciences, 22(4), 615-620.

Yu, XY. Ying, GG. \& Kookana, R. S. (2006). Sorption and desorption behaviors of diuron in soils amended with charcoal. Journal of Agricultural and Food Chemistry, 54(22), 8545-8550.

Zheng, W. Guo, M. Chow, T. Bennet, D. N. \& Rajagopalan, N. (2010). Sorption properties of greenwaste biochar for two triazine pesticides. Journal of Hazardous Materials, 181(1-3), 121-126. 